\title{
Manajemen Asuhan Keperawatan Jiwa Pada Tn.A Dengan Masalah Risiko Perilaku Kekerasan
}

\section{Azwara Andika Ginting}

\author{
azwaraandika@gmail.com
}

\section{BAB 1}

\section{LATAR BELAKANG}

\section{$1.1 \quad$ Latar Belakang}

Skizofrenia merupakan penyakit kronis, parah, dan melumpuhkan, gangguan otak yang di tandai dengan pikiran kacau, waham, delusi, halusinasi, dan perilaku aneh atau katatonik (Pardede, Siregar \& Halawa, 2020). Privalensi ganguan jiwa di Indonesia berdasarkan (Kemenkes, 2019), di urutan pertama Provinsi Bali 11,1\% dan nomor dua disusul oleh Provinsi DI Yogyakarta 10,4\%, NTB 9,6\%, Provinsi Sumatera Barat 9,1\%, Provinsi Sulawesi Selatan 8,8\%, Provinsi Aceh 8,7\%, Provinsi Jawa Tengah 8,7\%, Provinsi Sulawesi Tengah 8,2\%, Provinsi Sumatera Selatan 8\%, Provinsi Kalimantan Barat 7,9\%. Sedangkan Provinsi Sumatera Utara berada pada posisi ke 21 dengan privalensi 6,3\% (Kemenkes, 2019).

Skizofrenia adalah gangguan jiwa yang dapat berakhir dengan hilanngya dengan nyawa seseorang. Dalam penanganan penyakit ini karena jiwa yang tergangangu maka di butuhkan adalah terapi, rehabilitasi serta dengan konseling. Upaya terbesar untuk penangan penyakit gangguan jiwa terletak pada keluarga dan masyarakat, dalam hal ini terapi terbaik adalah bentuk dukungan keluarga dalam mencegah kambuhnya penyakit skizofrenia (Pitayanti, 2020). Tanda dan gejala yang timbul akibat skizofrenia berupa gejala positif dan negatif seperti perilaku kekerasan. Resiko perilaku kekerasan merupakan salah satu respon marah yang diespresikan dengan melakukan ancaman, mencederai diri sendiri maupun orang lain. Pada aspek 
fisik tekanan darah meningkat, denyut nadi dan pernapasan meningkat, marah, mudah tersinggung, mengamuk dan bisa mencederai diri sendiri. Perubahan pada fungsi kognitif, fisiologis, afektif, hingga perilaku dan sosial hingga menyebabkan resiko perilaku kekerasan. Berdasarkan data tahun 2017 dengan resiko perilaku kekerasan sekitar 0,8\% atau dari 10.000 orang menunjukkan resiko perilaku kekerasan sanggatlah tinggi (Pardede, Simanjuntak \& Laia, 2020).

Perilaku kekerasan merupakan salah satu respon terhadap streesor yang dihadapi oleh seseorang, respon ini dapat menimbulkan kerugian baik kepada diri sendiri, orang lain, maupun lingkungan. Seseorang yang mengalami perilaku kekerasan sering menunjukan perubahan perilaku seperti mengancam, gaduh, tidak bisa diam, mondar-mandir, gelisah, intonasi suara keras, ekspresi tegang, bicara dengan semangat, agresif, nada suara tinggi dan bergembira secara berlebihan. Pada seseorang yang mengalami resiko perilaku kekerasan mengalami perubahan adanya penurunan kemampuan dalam memecahkan masalah, orientasi terhadap waktu, tempat dan orang serta gelisah (Pardede \& Laia, 2020).

Risiko perilaku kekerasan timbul akibat rasa tidak nyaman dan panik yang terjadi akibat stressor dari dalam dan luar lingkungan. Perilaku kekerasan yang timbul pada klien skizofrenia diawali dengan adanya perasaan tidak berharga, takut dan ditolak oleh lingkungan sehingga individu akan menyingkir dari hubungan interpersonal dengan orang lain (Azis, 2018).

Risiko mencederai merupakan suatu tindakan yang memungkinkan dapat melukai atau membahayakan diri sendiri, orang lain, dan lingkungan sehingga masalah yang terjadi pada pasien parilaku kekerasan akan melibatkan keluarga (Suryeti, 2017). Survei awal pada skizofrenia ini dilakukan di Takengon subjek di dalam pembuatan askep ini berjumlah 1 orang dengan pasien resiko perilaku kekerasan atas nama inisial Tn.APenyebabnya Tn.Adi jadikan sebagai subjek dikarenakan pasien belum bisa mengatasi emosinya selain meminum obat. Maka tujuan asuhan 
keperawatan yang akan di lakukan ialah untuk mengajarkan standar pelaksaan resiko perilaku kekerasan/perilaku kekerasan pada saat Tn.Amengalami ke amukan.

\subsection{Rumusan Masalah}

Berdasarkan masalah yang telah di paparkan pada latar belakang maka rumusan masalah dalam askep ini yaitu Asuhan Keperawatan Resiko Perilaku Kekerasan Tn.Adi Takengon Aceh Tengah.

\subsection{Tujuan}

\subsubsection{Tujuan Umum}

Mahasiswa mampu memberikan asuhan keperawatan secara holistik dan komprehensif kepada Tn.Adengan gangguan resiko perilaku kekerasan di Takengon.

\subsubsection{Tujuan Khusus}

a. Mahasiswa mampu memahami pengertian, tanda dan gejala, etiologi, penatalaksanaan medis dan keperawatan resiko perilaku kekerasan.

b. Mahasiswa mampu melakukan pengkajian pada Tn.A dengan gangguan resiko perilaku kekerasan.

c. Mahasiswa mampu melakukan menegakkan diagnosa pada Tn.A dengan gangguan resiko perilaku kekerasan.

d. Mahasiswa mampu melakukan menetapkan perencanaan pada Tn.A dengan gangguan resiko perilaku kekerasan.

e. Mahasiswa mampu melakukan implementasi pada Tn.A dengan gangguan resiko perilaku kekerasan.

f. Mahasiswa mampu melakukan evaluasi pada Tn.A dengan gangguan resiko perilaku kekerasan.

g. Mendokumentasikan asuhan keperawatan yang diberikan pada Tn.A dengan gangguan resiko perilaku kekerasan. 


\section{BAB 2}

\section{LANDASAN TEORI}

\subsection{Resiko Perilaku Kekerasan}

\subsubsection{Pengertian}

Perilaku kekerasan merupakan respon maladaptif dari kemarahan, hasil dari kemarahan yang ekstrim ataupun panik. Perilaku kekerasan yang timbul pada klien skizofrenia diawali dengan adanya perasaan tidak berharga, takut,dan ditolak oleh lingkungan sehingga individu akan menyingkir dari hubungan interpersonal dengan oran lain (Pardede, Keliat \& Wardani, 2015). Perilaku kekerasan adalah salah satu respon terhadap stressor yang dihadapi oleh seseorang yang dihadapi oleh seeorang yang di tunjukan dengan perilaku kekerasan baik pada diri sediri maupun orang lain dan lingkungan baik secara verbal maupun non-verbal. Bentuk perilaku kekerasan yang dilakukan bisa amuk, bermusuhan yang berpotensi melukai, merusak baik fisik maupun kata-kata (Kio, 2020).

Perilaku kekerasan adalah suatu bentuk perilaku yang bertujuan melukai seseorang secara fisik maupun psikologis dapat terjai dalam dua bentuk yaitu saat berlangsung kekerasan atau riwayat perilaku kekerasan. Perilaku kekerasan merupakan respon maladaptif dari marah akibat tidak mampu klien untuk mengatasi strssor lingkungan yang dialaminya (Estika, 2021). Pemberian asuhan keperawatan merupakan proses terapeutik yang melibatkan hubungan kerjasama antara perawat dengan klien, keluarga atau masyarakat untuk mencapai tingkat kesehatan yang optimal.Tindakan keperawatan yang dilakukan kepada klien berupa tindakan keperawatan generalis. Pada penderita skizofrenia terdapat 2 gejala secara umum, yaitu berupa gejala positif dan gejala negatif. Gejala positif pada penderita skizofrenia antara lain timbulnya delusi/waham, halusinasi, gaduh 
gelisah, agresif, kekacauan alam pikiran. Gejala negatif meliputi sulit memulai pembicaraan, afek tumpul atau datar, berkurangnya motivasi, berkurangnya atensi, pasif, apatis dan penarikan diri secara sosial dan rasa tidak nyaman (Makhruzah, 2021)

\subsubsection{Tanda dan Gejala}

Tanda dan gerjala perilaku kekerasan adalah muka merah, tegang, mata melotot/pandangan tajam, bicara kasar, nada suara tinggi, membentak, kata-kata kotor, ketus, memukul benda/orang lain, menyerang orang lain, merusk lingkungan, amuk/agresif, jengkel, tidak berdaya, bermusuhan, mengamuk, ingin berkelahi, cerewet, kasar, berdebat, menyinggung perasaan orang lain, tidak peduli, kasar, penolakan, kekerasan, ejekan dan sindiran (Estika, 2021).

Tanda dan gejala perilaku kekerasan berdasarkan standar asuhan keperawatan jiwa dengan masalah resiko perilaku kekerasan, (Pardede, 2020) :

\section{Subjektif}

a. Mengungkapkan perasaan kesal atau marah.

b. Keinginan untuk melukai diri sendiri, orang lain dan lingkungan.

c. Klien suka membentak dan menyerang orang lain.

\section{Objektif}
a. Mata melotot/pandangn tajam.
b. Tangan mengepal dan Rahang mengatup.
c. Wajah memerah.
d. Postur tubuh kaku.
e. Mengancam dan Mengumpat dengan kata-kata kotor.
f. Suara keras.
g. Bicara kasar, ketus.
h. Menyerang orang lain dan Melukai diri sendiri/orang lain. 
i. Merusak lingkungan.

j. Amuk/agresif.

\subsubsection{Etiologi}

Penyebab dari perilaku kekerasan bukan terdiri cuman satu faktor tetapi termasuk juga faktor keluarga, media, teman, lingkungan, biologis. Perilaku kekerasan dapat menimbulkan dampak seperti gangguan psikologis, merasa tidak aman, tertutup, kurng percaya diri, resiko bunuh diri, depresi, harga diri rendah, ketidak berdayaan, isolasi sosial (Putri, 2020).

Faktor predisposisi yang menyebabkan terjadinya skizofrenia meliputi biologis, psikologis, dan sosialkultural, dimana faktor biologis yang mendukung terjadinya skizofrenia adalah genenitk, neuroanotomi, neurokimia, dan imunovirologi. Faktor presipitasi merupakan faktor stressor yang menjadikan klien mengalami sikizofrenia yang terdiri dari faktor biologi, psikologi, dan sosiokultural yang mampu menyebabkan risiko perilaku kekerasan, halusinasi, dan harga diri rendah (Pardede, Keliat \& Wardani, 2013).

Penyebab pasien beresiko untuk melakukan perilaku kekerasan disebabkan oleh cemas secara terus menerus, untuk itu dibutuhkan strategi preventif untuk mencegah perilaku kekerasan yang salah satunya adalah dengan melakukan teknik relaksasi. Terknik relaksasi merupakan salah satu yang sering digunakan untuk menghilangkan stress ialah Muscle Relaxation Therapy (PMRT). Terapi ini mudah di pelajari dan tidak terbatas, dampaknya bisa menggurangi kecemasan dan depresi, peningkatan perasaan kontrol diri dan peningkatan kemampuan koping dalam situasi stress (Pardede, 2020). Faktor psikologis yang menyebabkan pasien mengalami perilaku kekerasan antara lain yaitu : Keperibadian yang tertutup, kehilangan, aniaya seksual, kekerasan dalam keluarga (Pardede, 2020). 


\subsubsection{Faktor Predisposisi}

1. Faktor Psikologis

Psyschoanalytical Theory : Teori ini mendukung bahwa perilaku agresif merupakan akibat dari instinctual drives. Pandangan psikologi mengenai perilaku agresif mendukung pentingnya peran dari perkembana predisposisi atau pengalaman hidup. Beberapa contoh dari pengalaman hidup tersebut :

a. Kerusakan otak organik dan retardasi mental sehingga tidak mampu menyelesaikan secara efektif.

b. Rejeksi yang berlibihan saat anak-anak.

c. Terpapar kekerasan selama masa perkembangan.

2. Faktor Sosial Budaya

Sosial Learning Theory, ini merupakan bahwa agresif tidak berbeda dengan respon-respon yang lain, kultural dapat pula mempengaruhi perilaku kekerasan.

3. Faktor biologis

Neurotransmeiter yang sering dikaaitkan perilaku agresif dimana faktor pendukunya adalah masa kadankanak yang tidak menyengkan, sering mengalami kegagalan, kehidupan yang penuh tindakan agresif dan lingkungan yang tidak kondusif.

4. Perilaku

Reinfocemnt yang terima pada saat melakukan kekerasan dan sering mengobservasi kekerasan di rumah atau di luar rumah, semua aspek ini menstimulasi individu mengadopsi perilaku kekerasan. 


\subsubsection{Faktor Presitipasi}

Ketika seseorang merasa terancam terkadang tidak menyadari sama sekali apa yang menjadi sumber kemarahannya. Tetapi secara umum, seseorang akan mengerluarkan respon marah apabila merasa dirinya terancam. Faktor presipitasi bersumber dari klien, lingkungan, atau interaksi dengan orang lain. Faktor yang mencetuskan terjadinya perilaku kekerasan terbagi dua, yaitu (Parwati, 2018) :

a. Klien : Kelemahan fisik, keputusasaan, ketidak berdayaan, kurang percaya diri.

b. Lingkungan : Ribut, kehilangan orang atau objek yang berharga, konflik interaksi sosial.

\subsubsection{Implementasi}

Penatalaksaan perilaku kekerasan bisa juga dengan melakukan terapi restrain. Restrain adalah aplikasi langsung kekuatan fisik pada individu, tanpa injin individu tersebut, untuk mengatasi kebebasan gerak, terapi ini melibatkan penggunaan alat mekanis atau manual untuk membatasi mobilitas fisik pasien. Terapi restrain dapat diindikasikan untuk melindungi pasien atau orang lain dari cidera pada saat pasien lagi marah ataupun amuk (Hastuti, 2019).

Penanganan yang dilakukan untuk mengontrol perilaku kekerasan yaitu dengan cara medis dan non medis. Terapi medis yang dapat di berikan seperti obat antipsikotik adalah Chlorpoazine (CPZ), Risperidon (RSP) Haloperidol (HLP), Clozapin dan Trifluoerazine (TFP). Untuk terapi non medis seperti terapi generalis,untuk mengenal masalah perilaku kekerasan serta mengajarkan pengendalian amarah kekerasan secara fisik : nafas dalam dan pukul bantal, minum obat secara teratur, berkomunikasi verbal dengan baik- 
baik, spritual : beribadah sesuai keyakinan pasien dan terapi aktivitas kelompk (Estika, 2021).

\subsubsection{Terapi Medis}

Fsikomarmaka adalah terapi menggunakan obat dengan tujuan untuk mengurangi atau menghilanggan gejala gannguan jiwa. Dengan demiakian kepatutan mium obat adalah mengonsumsi obat yang direspkan oleh dokter pada waktu dan dosis yang tepat karena pengobatan hanya akan efektif apabila penderita memenuhi aturan dalam penggunaan obat (Pardede, Keliat \& Wardani, 2013).

\subsubsection{Tindakan Keperawatan}

Mengajarkan stimulasi persepsi perilaku kekerasan berdasarkan standar pelaksanaan untuk mengenal penyebab perilaku kekerasan dengan latihan fisik seperti : Tarik nafas dalam dan pukul kasur bantal, meminum obat dengan teratur, berbicara secara baik-baik seperti meminta sesuatu dan mengajarkan spritual sesuai kepercayaan pasien (Pardede \& Laia, 2020).

\subsubsection{Intervensi Keperawatan}

Rencana tindakan yang diberkan pada resiko perilaku kekerasan dengan memberikan terapi SP 1-4 tentang Resiko perilaku Kekerasan :

1. Latihan fisik 1: Tarik nafas dalam Latihan fisik 2 : pukul kasur bantal

2. Mengontrol perilaku kekerasan dengan cara minum obat

3. Komunikasi verbal asertif/ berbicara baik-baik

4. Spiritual

\subsubsection{Diagnosa Keperawatan}

1. Resiko perilaku kekerasan

2. Halusinasi

3. Harga Diri Rendah 



\section{BAB 3}

\section{TINJAUN KASUS}

\subsection{Pengkajian Keperawatan}

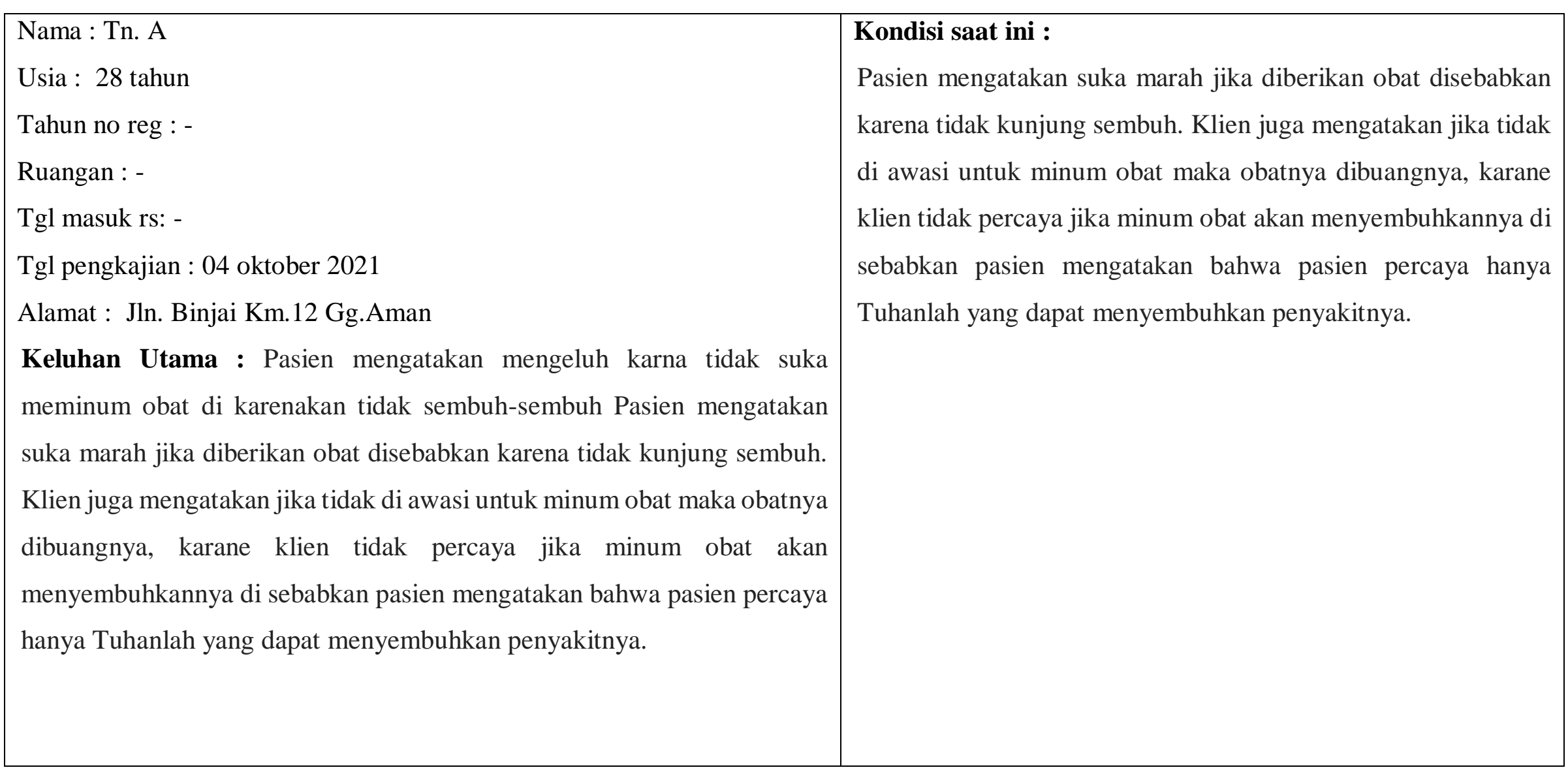


3.1.1 Faktor Predisposisi Dan Faktor Presipitasi

\begin{tabular}{|c|c|c|c|c|}
\hline \multirow[t]{2}{*}{ Faktor predisposisi } & \multicolumn{3}{|l|}{ Faktor presipitasi } & \multirow[t]{2}{*}{ STRESSOR } \\
\hline & Nature & Origin & $\begin{array}{l}\text { Number \& } \\
\text { Timing }\end{array}$ & \\
\hline $\begin{array}{l}\text { Biologis: } \\
\begin{array}{l}\text { 1. Resiko Perilaku Kekerasan } 2 \text { tahun yang lalu } \\
\text { 2. Harga Diri Rendah } \\
\text { 3. Tn.A tidak rutin melaksanakan check up }\end{array}\end{array}$ & 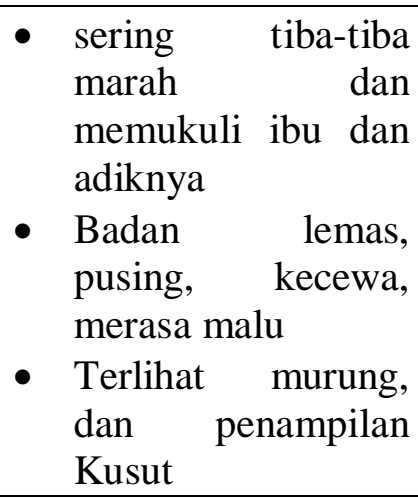 & Internal & $\begin{array}{l}\text { Sejak } 2 \text { tahun } \\
\text { yang lalu }\end{array}$ & $\begin{array}{l}\text { - Resiko Perilaku } \\
\text { Kekerasan } \\
\text { - Halusinasi } \\
\text { - Harga diri rendah }\end{array}$ \\
\hline $\begin{array}{l}\text { Psikologis : } \\
\begin{array}{l}\text { 1. Tn.A memiliki kepribadian yang tertutup } \\
\text { 2. Tn.A berpakain tidak rapi dan terlihat kusam } \\
\text { 3. Tatapan mata kosong } \\
\text { 4. Tn.A merasa malu karena tidak bisa melakukan } \\
\text { aktivitas dengan baik } \\
\text { 5. Merasa kecewa akan penyakit yang ia derita } \\
\text { 6. Klien merasa seperti diasingkan }\end{array}\end{array}$ & 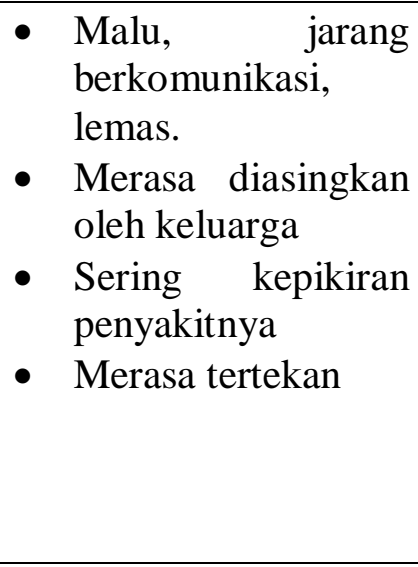 & Internal & $\begin{array}{l}\text { Sejak } 2 \text { tahun } \\
\text { yang lalu }\end{array}$ & $\begin{array}{l}\text { Kecewa, malu, } \\
\text { ketidakberdayaan, } \\
\text { merasa tertekan, cemas }\end{array}$ \\
\hline $\begin{array}{l}\text { Sosiocultural : } \\
\begin{array}{ll}\text { 1. } & \text { Tn.A seorang laki-laki berumur } 28 \text { Tahun } \\
\text { 2. } & \text { Tn.A Belum menikah } \\
\text { 3. } & \text { Sebelumnya Tn.A aktif terlibat dalam kegiatan }\end{array}\end{array}$ & & & & \\
\hline
\end{tabular}




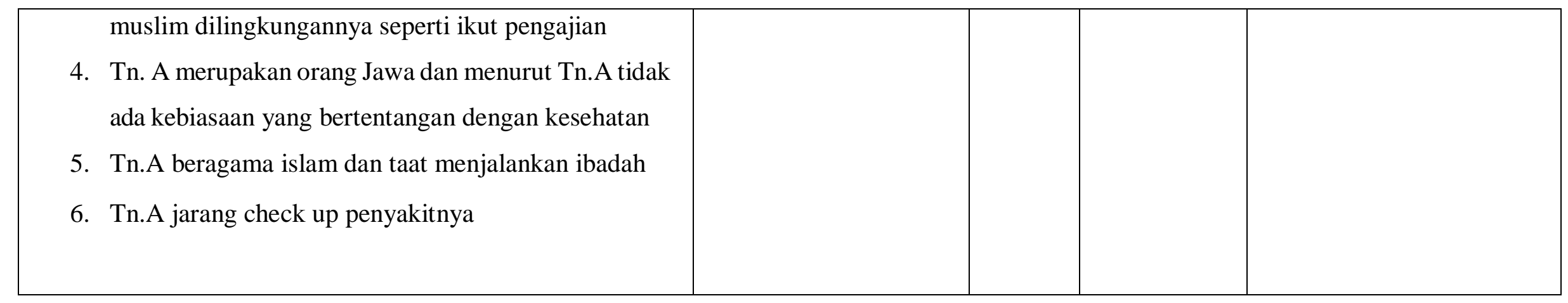

\section{Genogram}

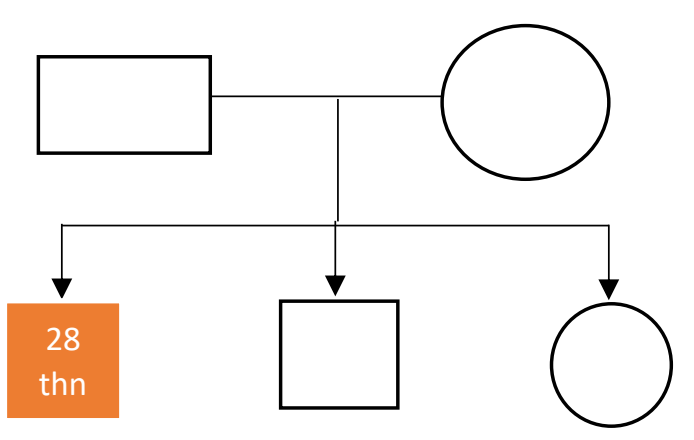

Tn. A masih memiliki kedua orang tua, mempunyai 3 bersaudara adik laki- laki dan adik perempuan, klien dirawat di rumah oleh keluarganya karena klien belum berstatus menikah. 


\subsubsection{Penilaian (Respon)Terhadap Stressor}

\begin{tabular}{|c|c|c|c|c|c|c|}
\hline STRESSOR & KOGNITIF & AFEKTIF & FISIOLOGIS & PERILAKU & SOSIAL & $\begin{array}{l}\text { DIAGNOSA } \\
\text { KEPERAWATAN }\end{array}$ \\
\hline $\begin{array}{l}\text { BIOLOGIS } \\
\text { - Resiko } \\
\text { Perilaku } \\
\text { Kekerasan } \\
\text { - Halusinasi } \\
\text { - Harga Diri } \\
\text { Rendah }\end{array}$ & $\begin{array}{l}\text { - } \text { Menurut Tn.A } \\
\text { penyakit Perilaku } \\
\text { Kekerasan } \\
\text { membuat ia malu, } \\
\text { dan kecewa } \\
\text { - } \text { Menganggap } \\
\text { penyakit yang } \\
\text { diderita serius } \\
\text { - Tidak tahu apa } \\
\text { yang harus } \\
\text { dilakukan untuk } \\
\text { penyakitnya } \\
\text { - berpakaian, } \\
\text { harus dibantu } \\
\text { oleh orang } \\
\text { sekitar, BAB } \\
\text { dan BAK juga } \\
\text { dibantu sering }\end{array}$ & $\begin{array}{l}\text { - Tn.A merasa } \\
\text { sedih, dan } \\
\text { marah-marah } \\
\text { bingung } \\
\text { dengan } \\
\text { kondisi } \\
\text { penyakitnya } \\
\text { Tn.A sering } \\
\text { berdiam diri } \\
\text { di depan } \\
\text { rumah } \\
\text { Klien terlihat } \\
\text { termenung, } \\
\text { padangan } \\
\text { kosong } \\
\text { Klien sering } \\
\text { mendengar } \\
\text { suara aneh } \\
\text { yang memrintahny } \\
\text { a }\end{array}$ & $\begin{array}{l}\text { - } \text { Pusing } \\
\text { - Sulit tidur } \\
\text { - Tidak nafsu } \\
\text { makan } \\
\text { - Tn.A tampak } \\
\text { lemas } \\
\text { - Pemeriksaan } \\
\text { TTV } \\
\text { TD: } 140 / 90 \\
\text { mmhg } \\
\text { N : } 80 \mathrm{x} / \text { menit } \\
\text { P: } 22 \times / \text { menit } \\
\text { S: } 37{ }^{0} \mathrm{C}\end{array}$ & $\begin{array}{l}\text { - Tn.A jarang } \\
\text { kontrol ke } \\
\text { rumah sakit } \\
\text { - Ekspresi } \\
\text { muka } \\
\text { sinis, } \\
\text { tampak } \\
\text { ingin } \\
\text { marah } \\
\text { Tn.A tampak } \\
\text { emosional } \\
\text { dan } \\
\text { merenggut }\end{array}$ & $\begin{array}{l}\text { - Pasien } \\
\text { mendatangi dan } \\
\text { menggunakan } \\
\text { fasilitas } \\
\text { kesehatan yang } \\
\text { ada untuk } \\
\text { mencari } \\
\text { kesembuhan } \\
\text { terhadap } \\
\text { masalah yang } \\
\text { dihadapi saat } \\
\text { ini }\end{array}$ & $\begin{array}{ll}\text { - Resiko Perilaku } & \\
\text { Kekerasan } & \\
\text { - Halusinasi } & \\
\text { - Harga } & \text { Diri } \\
\text { Rendah } & \end{array}$ \\
\hline
\end{tabular}




\begin{tabular}{|c|c|c|c|c|c|c|}
\hline & $\begin{array}{l}\text { mendengar } \\
\text { suara bisikkan } \\
\text { - jika diganggu } \\
\text { klien akan } \\
\text { marah, dan } \\
\text { melempar } \\
\text { sesuatu yang } \\
\text { terlihat di } \\
\text { depannya, } \\
\text { seperti } \\
\text { melempar batu, } \\
\text { kayu. }\end{array}$ & & & & & \\
\hline $\begin{array}{l}\text { PSIKOLOGIS } \\
\text { - sedih, cemas, } \\
\text { Kecewa, lemas, } \\
\text { pusing, marah- } \\
\text { marah, } \\
\text { pandangan } \\
\text { kosong }\end{array}$ & $\begin{array}{l}\text { - Tn.A tahu } \\
\text { bahwa badannya } \\
\text { menjadi lemah, } \\
\text { - Tn.A mengaku } \\
\text { bosan di rumah, } \\
\text { sering } \\
\text { mendengarkan } \\
\text { suara yang } \\
\text { memerintah } \\
\text { untuk dilakukan }\end{array}$ & $\begin{array}{l}\text { - Merasa kesal, } \\
\text { kecewa, dan } \\
\text { malu serta } \\
\text { tidak berdaya } \\
\text { dengan } \\
\text { penyakitnya } \\
\text { yang tidak } \\
\text { sembuh- } \\
\text { sembuh, dan } \\
\text { pandangan }\end{array}$ & $\begin{array}{l}\text { - } \text { Pusing } \\
\text { - } \text { Mual } \\
\text { sering } \\
\text { terbangun } \\
\text { apabila tidur } \\
\text { - Bahu terasa } \\
\text { tegang } \\
\text { - Tidak nafsu } \\
\text { makan }\end{array}$ & $\begin{array}{l}\text { - Tampak } \\
\text { cemas, } \\
\text { kecewa } \\
\text { dan } \\
\text { tidaktenan } \\
\text { g } \\
\text { - Kadang } \\
\text { Tn.A } \\
\text { tampak } \\
\text { murung } \\
\text { - Tn.A } \\
\text { tampak } \\
\text { gelisah } \\
\text { Tn.A } \\
\text { tampak }\end{array}$ & $\begin{array}{l}\text { - Hubungan } \\
\text { Tn.A dengan } \\
\text { Keluarga } \\
\text { Kurang baik } \\
\text { - Tn.A kurang } \\
\text { bersosialisasi } \\
\text { dengan } \\
\text { keluarga } \\
\text { Tn.A jarang } \\
\text { mengikuti } \\
\text { program } \\
\text { pengobatan } \\
\text { yang } \\
\text { diberikan } \\
\text { kepadanya }\end{array}$ & $\begin{array}{l}\text { - } \quad \text { ketidakberdayaan } \\
\text { Penampilan peran } \\
\text { tidak efektif }\end{array}$ \\
\hline
\end{tabular}




\begin{tabular}{|c|c|c|c|c|c|c|}
\hline & $\begin{array}{l}\text { - Tn.A tidak tahu } \\
\text { pengobatan } \\
\text { seperti apa lagi } \\
\text { yang dapat } \\
\text { dilakukan untuk } \\
\text { mengobati } \\
\text { penyakitnya. }\end{array}$ & kosong. & \begin{tabular}{|l} 
- Tn.Atampak \\
lemas \\
- Wajah \\
Tn.Atampak \\
lemas \\
- Wajah \\
Tn.Atampak \\
pucat \\
- Pemeriksaan \\
TTV \\
TD: $140 / 90$ \\
mmhg \\
$\mathrm{N}: 85 \times$ x $/$ menit \\
P : $20 \times$ x /menit \\
S: $36{ }^{0} \mathrm{C}$
\end{tabular} & $\begin{array}{l}\text { pasif dalam } \\
\text { menerima } \\
\text { perawatan } \\
\text { Tn.Amenunju } \\
\text { kkan raut } \\
\text { muka } \\
\text { merenggut } \\
\text { saat bercerita }\end{array}$ & $\begin{array}{l}\text { akan tetapi } \\
\text { sikap } \\
\text { Tn.Apasif } \\
\text { dalam } \\
\text { menerima } \\
\text { perawatan }\end{array}$ & $\begin{array}{l}\text { - Resiko perilaku } \\
\text { kekerasan }\end{array}$ \\
\hline \begin{tabular}{l}
$\quad$ SOSIAL \\
\multicolumn{1}{c|}{ BUDAYA } \\
- sering \\
Memikirkan \\
anak-anak \\
yang masih \\
jauh dari \\
rumah merasa \\
kasihan kepada \\
keluarga yang \\
harus menjaga
\end{tabular} & $\begin{array}{l}\text { Tn.A merasa } \\
\text { tidak berdaya } \\
\text { dengan } \\
\text { keadaannya } \\
\text { sejarang yang } \\
\text { tidak bisa } \\
\text { bekerjabingung } \\
\text { memikirkan anak- } \\
\text { anak yang } \\
\text { merawatnya } \\
\text { menurut pasien, } \\
\text { dukungan }\end{array}$ & $\begin{array}{l}\text { - Merasa } \\
\text { khawatir dan } \\
\text { sedih kepada } \\
\text { Keluarga dan } \\
\text { anak- } \\
\text { anaknya } \\
\text { yang } \\
\text { merawatnya } \\
\text { setiap hari } \\
\text { Merasa } \\
\text { bersalah } \\
\text { karena }\end{array}$ & $\begin{array}{l}\text { - } \text { Pusing } \\
\text { - Mulut tampak } \\
\text { kering } \\
\text { - Sulit tidur } \\
\text { - Bahu terasa } \\
\text { tegang } \\
\text { - Konstipasi } \\
\text { - Tidak nafsu } \\
\text { makan } \\
\text { - Tn. A tampak } \\
\text { lemas }\end{array}$ & $\begin{array}{l}\text { - Kontak mata } \\
\text { ada tapi tidak } \\
\text { bertahanlama } \\
\text { - Volume } \\
\text { suara } \\
\text { mengecil } \\
\text { - Tn. A } \\
\text { tampak } \\
\text { gelisah }\end{array}$ & $\begin{array}{l}\text { - Hubungan } \\
\text { Tn. A dengan } \\
\text { Keluarga baik } \\
\text { - Hubungan } \\
\text { Tn.A dengan } \\
\text { petugas } \\
\text { kesehatan } \\
\text { baik tetap } \\
\text { Tn.A mengikuti } \\
\text { program } \\
\text { pengobatan }\end{array}$ & $\begin{array}{l}\text { Ansietasketidakbe } \\
\text { rdayaan } \\
\text { - } \\
\text { Penampilan peran } \\
\text { tidak efektif }\end{array}$ \\
\hline
\end{tabular}




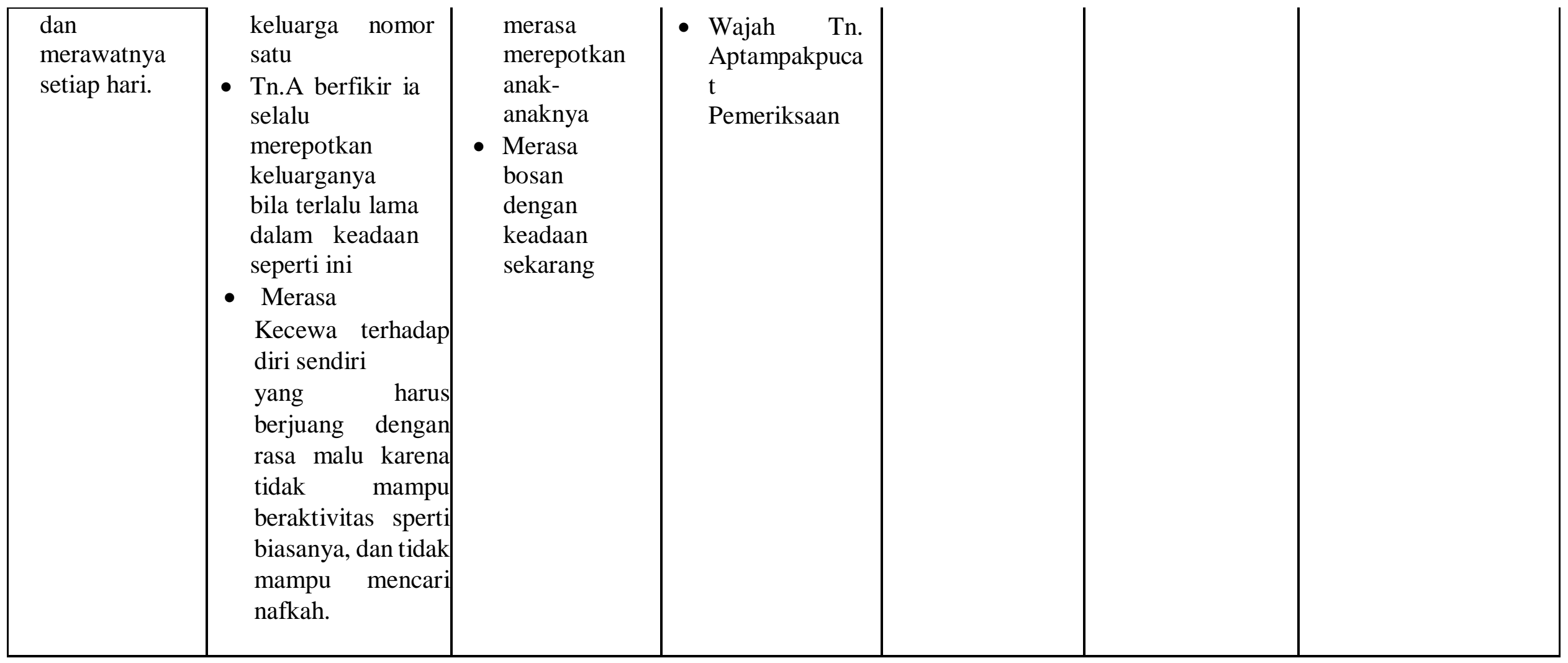

\subsubsection{Sumber Koping}

\begin{tabular}{|c|c|c|c|c|c|}
\hline $\begin{array}{c}\text { DIAGNOSA } \\
\text { KEPERAWATAN }\end{array}$ & PERSONAL ABILITY & SOSIAL & MATERIAL & POSITIE \\
SUPPORT & ASSETS & TELIEFS \\
\hline
\end{tabular}




\begin{tabular}{|c|c|c|c|c|c|}
\hline $\begin{array}{l}\text { - Resiko Perilaku } \\
\text { Kekerasan } \\
\text { - Halusinasi } \\
\text { - Harga diri } \\
\text { rendah } \\
\text { - Kecemasan }\end{array}$ & $\begin{array}{l}\text { - Tn.A mampu } \\
\text { mengungkapkan } \\
\text { perasaan cemas } \\
\text { - Tn.A mengatakan bila } \\
\text { cemasnya memuncak } \\
\text { maka ia akan berdiam } \\
\text { diri dan berdoa }\end{array}$ & $\begin{array}{l}\text { - Tn.A mendapat } \\
\text { dukungan dari } \\
\text { keluarga untuk } \\
\text { kesembuhannya } \\
\text { terutama dari istri } \\
\text { Anak-anaknya } \\
\text { - Anak-anak Tn. A } \\
\text { bergantian } \\
\text { merawat pasien }\end{array}$ & $\begin{array}{l}\text { - Sosial ekonomi Tn. } \\
\text { A menengah } \\
\text { Pengobatan } \\
\text { ditanggung BPJS } \\
\text { - Jarak rumah Tn.A } \\
\text { dengan tempat } \\
\text { pelayanan } \\
\text { kesehatan cukup } \\
\text { jauh }\end{array}$ & $\begin{array}{ll}\text { - } & \text { Tn.A percaya } \\
\text { bahwa petugas } \\
\text { kesehatan akan } \\
\text { membantunya } \\
\text { - } \\
\text { Tn.A berharap cepat } \\
\text { sembuh agar tidak } \\
\text { merepotkan } \\
\text { Suaminya }\end{array}$ & $\begin{array}{l}\text { Terapi spesialis: } \\
\text { Terapi spesialis: } \\
\text { - } \\
\text { Sp 1-4 Resiko } \\
\text { Perilaku } \\
\text { Kekerasan } \\
\text { - Menghardiks } \\
\text { - Sp 1-4 } \\
\text { halusinasi } \\
\text { - Tarik Nafas } \\
\text { Dalam }\end{array}$ \\
\hline $\begin{array}{l}\text { - Penampilan peran } \\
\text { tidak efektif }\end{array}$ & $\begin{array}{l}\text { - } \text { Tn.A dapat } \\
\text { menyebutkan } \\
\text { penyebab penampilan } \\
\text { peran tidak efektif } \\
\text { - Tn.A } \\
\text { menganggap } \\
\text { dirinya tidak } \\
\text { mampu sebagai } \\
\text { pengganti akibat } \\
\text { kondisi yang } \\
\text { dialami } \\
\text { Tn.A merasa } \\
\text { tidak berdaya } \\
\text { karena tidak } \\
\text { mampu memberi } \\
\text { nafkah kepada }\end{array}$ & & & $\begin{array}{l}\text { - Tn.A selalu } \\
\text { berdoa untuk } \\
\text { kesembuhan } \\
\text { penyakitnya } \\
\text { - Tn.A yakin, bila ia } \\
\text { mengikuti } \\
\text { petunjuk dan saran } \\
\text { dari petugas } \\
\text { kesehatan maka ia } \\
\text { akan cepat sembuh } \\
\text { Tn.A yakin suami } \\
\text { dan keluarga } \\
\text { mendukung } \\
\text { supaya lekas } \\
\text { sembuh }\end{array}$ & \\
\hline
\end{tabular}




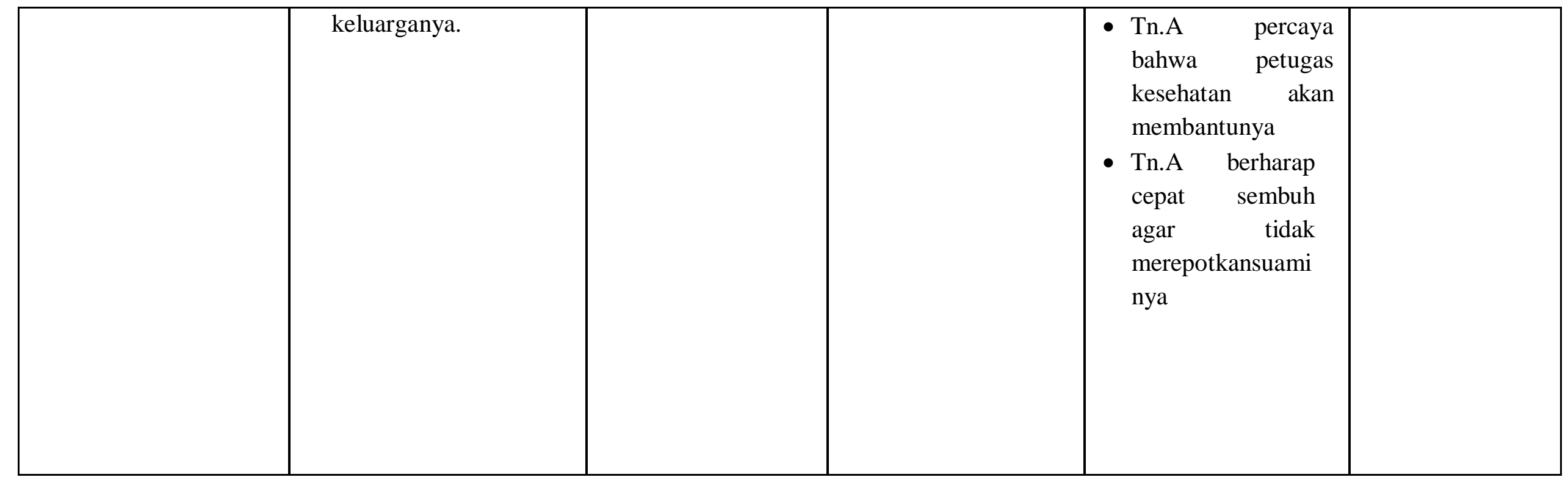




\begin{tabular}{|c|c|c|c|c|c|}
\hline Kurang pengetahuan & $\begin{array}{l}\text { - Tn.A mampu mengenal } \\
\text { dan menilai } \\
\text { Komplikasi dari } \\
\text { penyakitnya } \\
\text { - } \text { Tn.A mampu } \\
\text { melatih cara hidup } \\
\text { sehat }\end{array}$ & $\begin{array}{l}\text { - Tn.A mendapat } \\
\text { dukungan dari } \\
\text { keluarga untuk } \\
\text { kesembuhannya } \\
\text { terutama dari } \\
\text { anak-anaknya } \\
\text { - Tn.A dibantu oleh } \\
\text { keluarganya } \\
\text { bergantian } \\
\text { menjaga dan } \\
\text { membatu Klien } \\
\text { dalam pemenuhan } \\
\text { pemberian makan, } \\
\text { minum BAB,BAK } \\
\text { Tetangga Tn.A } \\
\text { dan lingkungan } \\
\text { daerah } \\
\text { rumahnya } \\
\text { sering } \\
\text { berkunjung } \\
\text { kerumah } \\
\text { melihat kadaan } \\
\text { Klien }\end{array}$ & $\begin{array}{l}\text { - Sosial ekonomi } \\
\text { Tn.A menengah } \\
\text { - Tn.A tinggal di } \\
\text { rumah bersama } \\
\text { keluarga istri dan } \\
\text { anaknya } \\
\text { - Sarana dan } \\
\text { prasarana } \\
\text { tersedia } \\
\text { - Biaya } \\
\text { pengobatan } \\
\text { ditanggung oleh } \\
\text { asuransi BPJS } \\
\text { Jarak rumah Tn.A } \\
\text { dengan tempat } \\
\text { pelayanan } \\
\text { kesehatan } \\
\text { (RSMM) cuku } \\
\text { jauh, harus } \\
\text { menggunakan } \\
\text { transportasi }\end{array}$ & $\begin{array}{l}\text { - Tn.A percaya } \\
\text { bahwa petugas } \\
\text { kesehatan akar } \\
\text { membantunya } \\
\text { - Tn.A berharap } \\
\text { cepat sembuh } \\
\text { agar tidak } \\
\text { merepotkan } \\
\text { suaminya } \\
\text { - Tn.A selalu } \\
\text { berdoa untuk } \\
\text { kesembuhan } \\
\text { penyakitnya } \\
\text { Tn.A yakin, bila } \\
\text { ia mengikuti } \\
\text { petunjuk dan } \\
\text { saran dari petugas } \\
\text { kesehatan maka } \\
\text { ia akan cepat } \\
\text { sembuh } \\
\text { Tn. A yakin } \\
\text { anak-anakdan } \\
\text { keluarga } \\
\text { mendukung } \\
\text { supaya lekas } \\
\text { sembuh }\end{array}$ & $\begin{array}{l}\text { Terapi generalis: } \\
\text { - SP } \quad \text { kurang } \\
\quad \text { pengetahuan } \\
\text { Terapi spesialis: } \\
\text { Terapi suportif, } \\
\text { FPE }\end{array}$ \\
\hline
\end{tabular}




\subsubsection{Mekanisme Koping}

\begin{tabular}{|c|c|}
\hline $\begin{array}{l}\text { HAL YANG } \\
\text { DILAKUKAN }\end{array}$ & ANALISA \\
\hline $\begin{array}{l}\text { - Tn.A mengatakan bila ada masalah, dia lebih emosional, sering } \\
\text { memukuli ibunya } \\
\text { - Bila sakit Tn.A berobat ke pelayanan kesehatan } \\
\text { - Tn. A taat menjalankan ibadah sesuai dengan keyakinannya } \\
\text { - Tn. A selalu berdoa kepada Allah SWT untuk kesembuhannya }\end{array}$ & $\begin{array}{l}\text { - Konstruktif: } \\
\checkmark \text { Tn.A mengatakan bila ada masalah, dia lebih } \\
\text { emosional, sering memukuli ibunya } \\
\checkmark \text { Bila sakit Tn.A berobat ke pelayanan kesehatan } \\
\checkmark \text { Tn.A taat menjalankan ibadah sesuai } \\
\text { dengan keyakinannya } \\
\checkmark \text { Tn.A selalu berdoa kepada Allah SWT } \\
\text { untuk kesembuhannya. }\end{array}$ \\
\hline & - Destruktif : - \\
\hline
\end{tabular}




\subsubsection{Status Mental}

\begin{tabular}{|l|l|}
\hline 1. Penampilan & Bersih, rapi, tidak tercium bau, Tn.A tampak lemas \\
\hline 2. Pembicaraan & Mampu berbicara dengan baik, namun suara pelan \\
\hline 3. Aktivitas motoric & Tubuh sulit digerakkan \\
\hline 4. Interaksi selamawawancara & Cukup kooperatif \\
\hline 5. Alam perasaan & $\begin{array}{l}\text { Emosional, Sedih, merasa cemas, malu, kecewa takut dan bingung mengenai kondisi penyakit, yang ia } \\
\text { derita }\end{array}$ \\
\hline 6. Afek & Datar \\
\hline 7. Persepsi & Tn.A mengalami gangguan dalam proses sensori-persepsi \\
\hline 8. Isi piker & Mengalami masalah karena sebagian memori terlupakan \\
\hline 9. Proses piker & masalah karena sebagian memori terlupakan \\
\hline 10. Tingkat kesadaran & Tn.A dapat menyebutkan kembali nama istri \\
\hline 11. Daya ingat & Tn.A tidak dapat mengingat beberapa kejadian dalam hidupnya \\
\hline 12. Kemampuan berhitung & Kemampuan berhitung cukup baik \\
\hline 13. Penilaian & Tn.A belum mampu menyebutkan bagaimana caranya agar Tn. Aplekas sembuh \\
\hline 14. Daya tilik diri & $\begin{array}{l}\text { Tn.A menyadari bahwa saat ini ia sedang sakit, Tn.A hanya bisa berdoa supaya lekas sembuh agar } \\
\text { tidak terus merepotkan keluarganya Tn.A menyadari ia memiliki anak-anak dan keluarga yang } \\
\text { menyayanginya dan mendukung kesembuhannya }\end{array}$ \\
\hline
\end{tabular}

Kesimpulan : Mental Status Examination (MSE) mengalami masalah gangguan jiwa, gangguan Tn. A yaitu : Resiko Perilaku

Kekerasan. 


\subsection{Diagnosa Dan Terapi}

\begin{tabular}{|l|l|}
\hline DIAGNOSA KEPERAWATAN DAN TERAPI KEPERAWATAN & DIAGNOSA MEDIS \\
\hline 1. Sp 1-4 Resiko Perilaku Kekerasan & Skizofrenia \\
1. Latihan fisik: -Tarik nafas dalam & \\
2. Pukul kasur batal & \\
3. Mengenal perilaku kekerasan dengan cara minum obat teratur & \\
4. Komunikasi verbal : asertif/ berbicara baik-baik & 5. Spiritual \\
2. Sp1-4 Halusinasi & 1. Mengidentifikasi isi frekuensi waktu terjadi, mengontrol halusinasi \\
& 2. Mengontrol halusinasi dengan meminum obat secara teratur \\
& 3. Mengontrol halusinasi dengan bercakap cakap dengan orang lain \\
& 4. Mengontrol halusinasi dengan melakukan kegiatan terjadwal \\
3. Sp 1-4 Harga Diri Rendah & \\
- Mengidentifikasi kemampuan aspek positif yang dimiliki & \\
- Menilai kemampuan yang dipilih & Melatih kegiatan sesuai kemampuan \\
4. Penampilan peran tidak efektif & \\
Terapi perilaku & Kurang pengetahuan \\
Terapi suportif, FPE & \\
\hline
\end{tabular}




\subsection{Implementasi Tindakan Kperawatan Dan Evaluasi}

\begin{tabular}{|c|c|}
\hline IMPLEMENTASI TINDAKAN KPERAWATAN & EVALUASI \\
\hline $\begin{array}{l}\text { Tanggal : 04-14 Oktober } 2021 \\
\text { Jam : } 08.00-14.00 \text { wib } \\
\text { 1. Menenangkan pasien } \\
\text { 2. Memahami keadaan pasien } \\
\text { 3. Mendiskusikan penyebab,terjadinya prosest erjadi, tanda gejala,akibat } \\
\text { 4. Mengkaji tingkat ansietas } \\
\text { 5. Melatih pasien teknik relaksasi fisik tarik nafas dalam } \\
\text { 6. Melatih pasien mengatasi ansietas dengan ditraksi dan hipnotis lima } \\
\text { 7. Mengkaji kegiatan spritual pasien } \\
\text { 8. Mendukung keterlibatan keluarga dengan cara yang tepat }\end{array}$ & $\begin{array}{l}\text { Resiko Prilaku Kekeran } \\
\text { Hari Pertama : 04-10-2021 (10:30) } \\
\text { S : Klien terlihat senang dan antusias } \\
\text { O : Tarik nafas dalam, pukul kasur bantal } \\
\text { A : Resiko Prilaku Kekerasan (+) } \\
\text { P : Intervensi dilanjutkan } \\
\text { Hari Kedua : 05-10-2021 (09:30) } \\
\text { S : Klien terlihat senang dan antusias } \\
\text { O : Komunikasi secara verbal : asertif/bicara baik-baik } \\
\text { A : Resiko Prilaku Kekerasan (+) } \\
\text { P : Intervensi dilanjutkan } \\
\text { Hari Ketiga : 06-10-2021 (11:30) }\end{array}$ \\
\hline
\end{tabular}




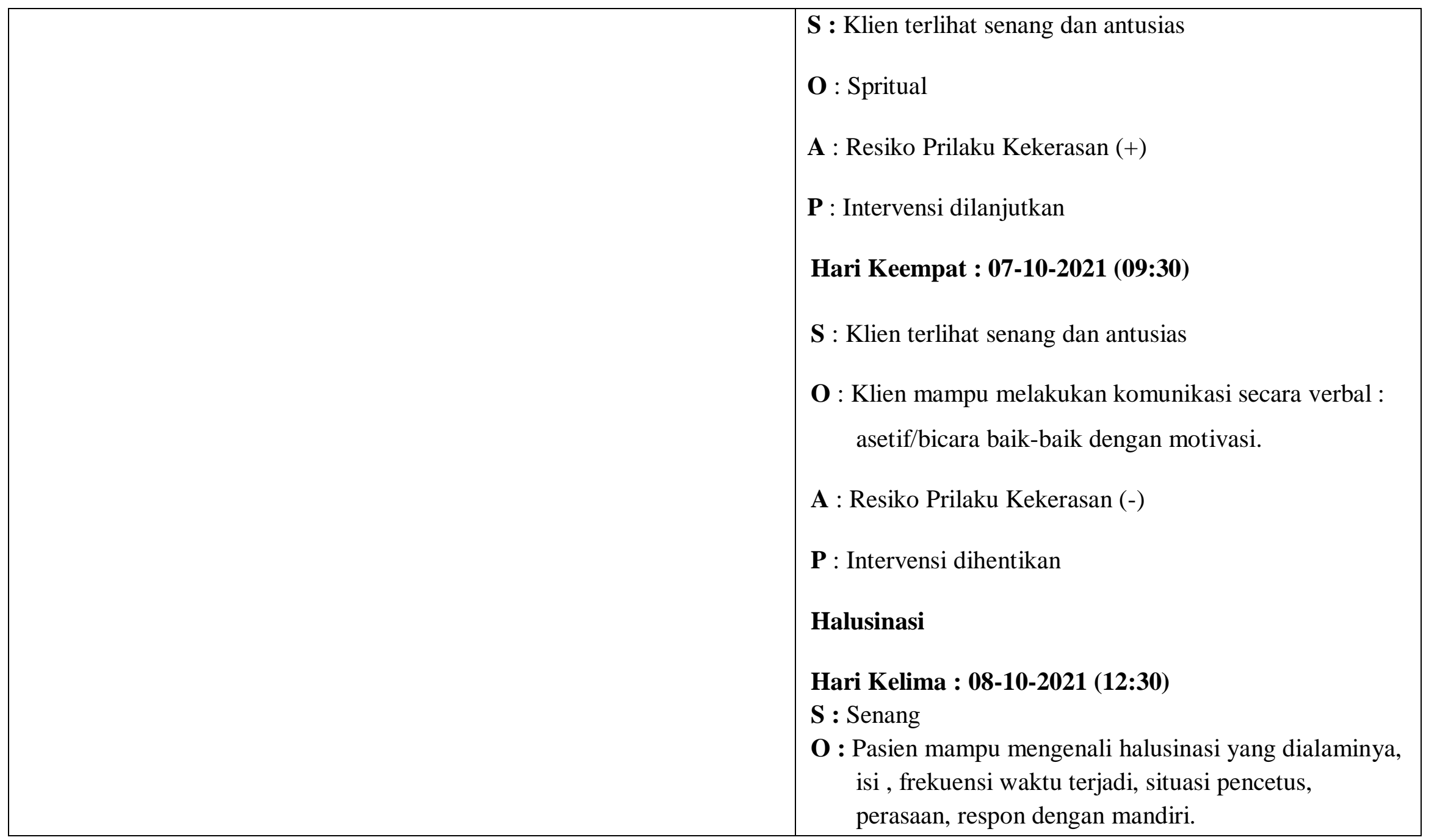




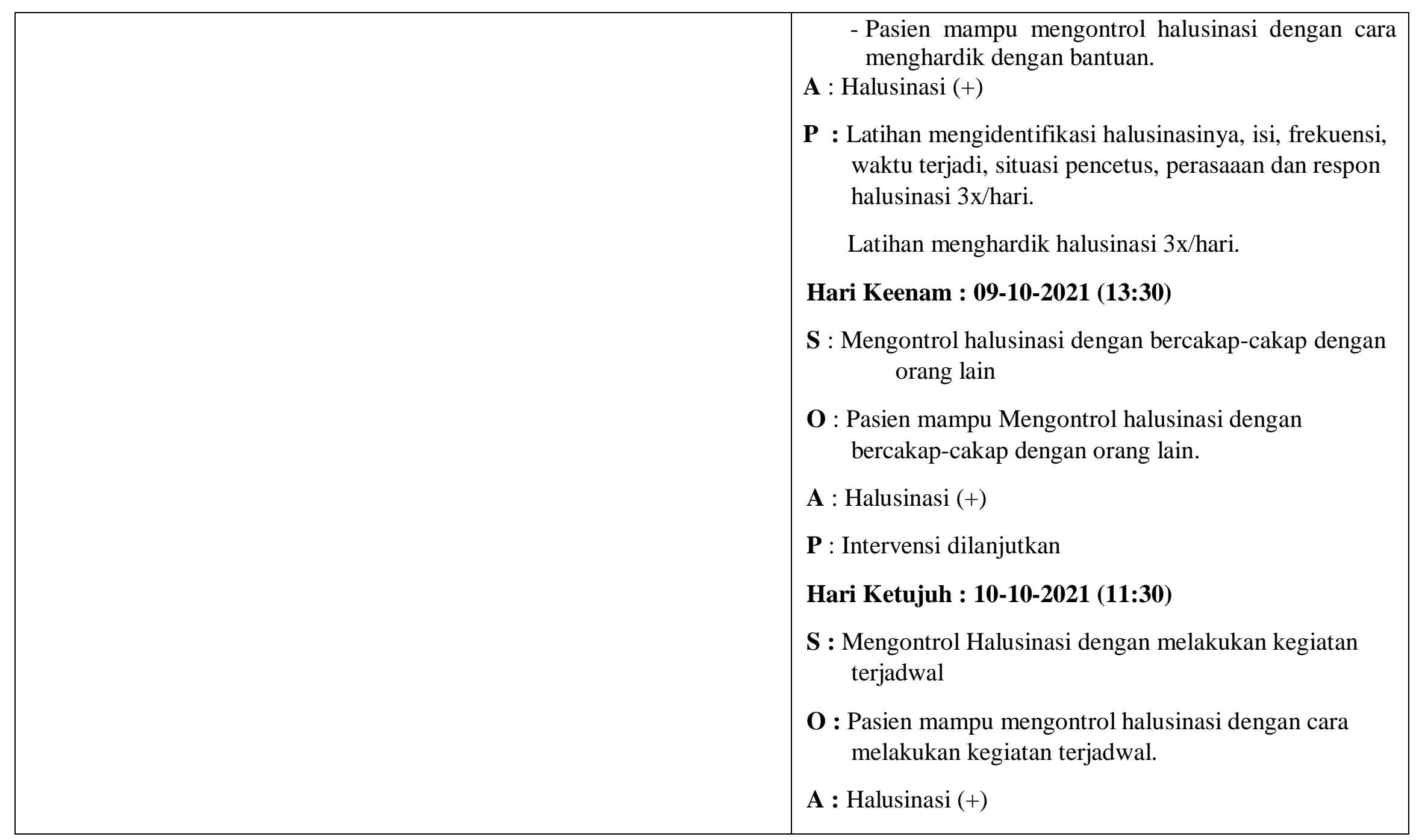




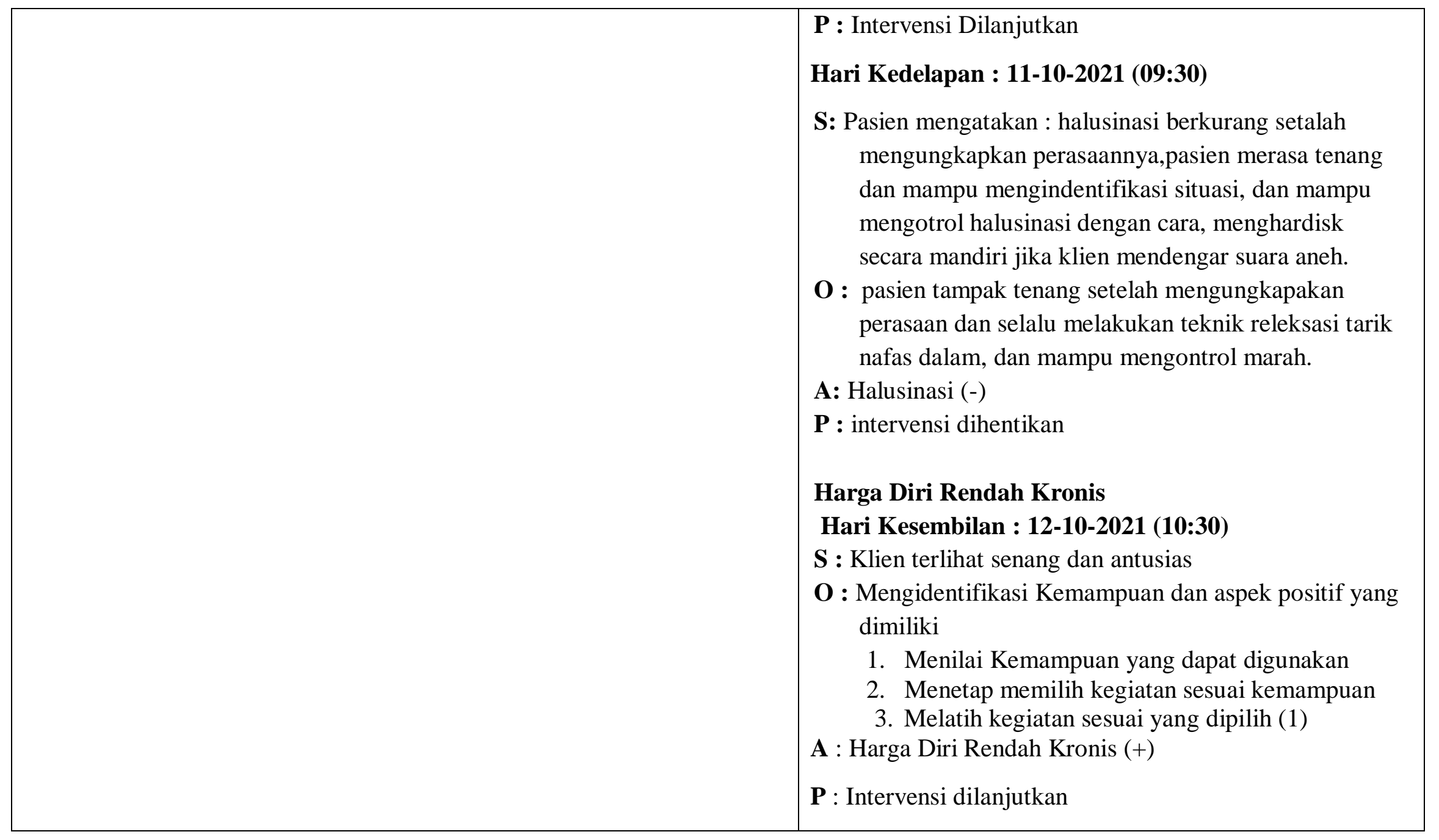




\begin{tabular}{|l|l|}
\hline Hari Kesepuluh : 13-10-2021 (11:30) \\
S : Klien terlihat senang dan antusias \\
$\mathbf{O}:$ Melatih kegiatan sesuai kemampuan (2) \\
A : Harga Diri Rendah Kronis (+) \\
P : Intervensi dilanjutkan \\
Hari Kesebelas : 14-10-2021 (13:30) \\
S : Klien terlihat senang dan antusias \\
O : Melatih kegaiatn sesuai kemampuan (3) \\
A : Harga Diri Rendah Kronis (-) \\
P : Intervensi dihentikan
\end{tabular}




\section{BAB 4}

\section{PEMBAHASAN}

\subsection{Tahap Pengkajian}

Selama pengkajian dilakukan pengumpulan data dari beberapa sumber yaitu dari pasien dan keluarga . penulis melakukan pendekatan pada pasien melalui komunikasi terapautik yang lebih terbuka membantu pasien untuk memecahkan perasaannya dan juga melakukan observasi kepada pasien. Adapau upaya tersebut yaiut :

a. Melakukan pendekatan dan membina hubungan saling percaya diri pada pasien agar pasien lebih terbuka dan lebih percaya dengan menggunakan perasaan.

b. Mengadakan pengkajian pasien dengan wawancara dan tidak menemukan kesenjangan karena di temukan hal sama seperti diteori bahwasanya Perilaku kekerasan merupakan respon maladaptif dari kemarahan, hasil dari kemarahan yang ekstrim ataupun panik. Perilaku kekerasan yang timbul pada klien skizofrenia diawali dengan adanya perasaan tidak berharga, takut,dan ditolak oleh lingkungan sehingga individu akan menyingkir dari hubungan interpersonal dengan oran lain (Pardede, Keliat \& Wardani, 2015).

\subsection{Intervensi}

Perencanaan dalam proses keperawatan lebih di kenal dengan asuhan keperawatan yang merupakan tahap selanjutnya setelah pengkajian dan penentuan diagnosa keperawatan. Pada tahap perencanaan mahasiswa hanya menyusun rencan tindakan keperawatan Risiko Perilaku Kekerasan dan Perilaku Kekerasan. Pada tahap ini antara tinjauan teroritis dan tinjauan kasus tidak ada kesenjangan sehingga mahasiswa dapat melaksanakan tindakan seoptimal mungkin di dukung dengan seringnya bimbingan dengan pembimbing. Secara teoritis digunakan secara strategi pertemuan sesuai 
dengan diagnosa keperawatan yang muncul saat pengkajian. Adapun upaya yang digunakan mahasiswa ialah :

1. Risiko Perilaku Kekerasan

a. Mengidentifikasikan isi Risiko Perilaku Kekerasan.

b. Mengidentifikasikan waktu terjadi Risiko Perilaku Kekerasan.

c. Mengidentifikasikan situasi pencetus Risiko Perilaku Kekerasan.

d. Mengidentifikasikan respon terhadap Risiko Perilaku Kekerasan.

e. Membantu pasien mempraktekkan latihan cara mengontrol Risiko Perilaku Kekerasan dengan tarik nafas dalam dan pukul bantal.

f. Menjelaskan cara mengontrol Perilaku Kekerasan dengan minum obat secara teratur.

g. Melatih pasien mengotrol Risiko Perilaku Kekerasan dengan berbicara baik-baik dengan orang lain dan spritual.

h. Mengevalusi jadwal kegiatan harian pasien.

\subsection{Tahap Implementasi}

Pada tahap implementasi mahasiswa hanya mengatasi masalah keperawatan dengan diagnosa keperawatan Risiko perilaku Kekerasan/Perilaku Kekerasank karena masalah utama yang dialami pasien. Pada diagnosa keperawatan Risiko Perilaku Kekerasan/Perilaku Kekerasan strategi pertemuan ialah mengidentifikasi perilaku kekerasan, mengotrol perilaku kekerasan, dan cara tarik nafas dalam dan pukul bantal kasur. Strategi pertemuan yang kedua ialah anjurkan minum obat secara teratur, strategi pertemua ketiga ialah latihan cara komunikasi secara verbal atau bicara baikbaik dan strategi terakhir pertemua keempat yaitu spritual.

\subsection{Tahap Evaluasi}

Pada tinjauan kasus evaluasi yang dihasilkan adalah :

1. Klien sudah dapat mengontrol dan mengidentifikasi Risiko Perilaku Kekerasan. 
2. Klien dapat mengendalikan Risiko Perilaku Kekerasan melalui latihan fisik.

3. Klien dapat mengendalikan Risiko Perilaku Kekerasan dengan cara pergi ke poli jiwa untuk mendapatkan minum obat.

4. Klien dapat mengendalikan Risiko Perilaku Kekerasan dengan berbicara baik-baik dengan orang lain.

5. Klien dapat mengendalikan Risiko Perilaku Kekerasan dengan melakukan spritual terjadwal. 


\section{BAB 5}

\section{PENUTUP}

\subsection{Kesimpulan}

Setelah menguraikan tentang proses keperawatan pada Tn.A dan disimpulkan bahwa pasien dapat mengontrol risiko perilaku kekerasan dengan terapi yang di ajarkan oleh mahasiwa. Dimana pasien dapat melakukan tarik nafas dalam, memukul bantal secara mandiri untuk mengontrol amarahnya. Pasien juga minum obat secara teratur dan berbicara secara baik-baik jika ingin meminta sesuatu atau melakukan penolakan, hingga pasien dapat melakukan spritual sesuai ajaran agama yang dianut.

\subsection{Saran}

1. Diharapkan pada keluarga sering mengunjungi pasien selama waktu perawatan karena dengan seringnya keluarga berkunjung, maka pasien merasa berarti dan dibutuhkan dan juga setelah pulang keluarga harus memperhatikan obat dikonsumsi seta membawa pasien kontrol secara teratur kepelayana kesehatan jiwa ataupun rumah sakit jiwa.

2. Bagi mahasiswa /mahasiwi agar lebih memperdalam ilmu pengetahuan khusus tentang keperawatan jiwa. 


\section{DAFTAR PUSTAKA}

Azis, N. R., Sukamto, E., \& Hidayat, A. (2018). Pengerun Terapi De-Ekslasi Terhadap Perubahan Perilaku Pasien dengan Resiko Perilaku Kekerasan di Rumah Sakit Jiwa Daerah Atma Husada Mahakam Samarinda. http://repository.poltekkes-kaltim.ac.id/id/eprint/797

Estika Mei Wulansari, E. (2021). Asuhan Keperawatan Jiwa Pada Pasien Dengan Risiko Perilaku Kekerasan di Rumah Sakit Daerah dr Arif Zainuddin Surakarta (Doctoral dissertation, Universitas Kusuma Husada Surakarta). http://eprints.ukh.ac.id/id/eprint/1020

Hastuti, R. Y., Agustina, N., \& Widiyatmoko, W. (2019). Pengaruh restrain terhadap penurunan skore panss EC pada pasien skizofrenia dengan perilaku kekerasan. Jurnal Keperawatan Jiwa, 7(2), 135-144. https://jurnal.unimus.ac.id/index.php/JKJ/article/view/4907/pdf

Kio, A. L., Wardana, G. H., \& Arimbawa, A. G. R. (2020). Hubungan Dukungan Keluarga terhadap Tingkat Kekambuhan Klien dengan Resiko Perilaku Kekerasan. Caring: Jurnal Keperawatan, 9(1), 69-72. http://ejournal.poltekkesjogja.ac.id/index.php/caring/article/view/5 $\underline{92}$

Kemenkes RI. (2019). Riset Kesehatan Dasar, RISKESDAS.Jakarta: Kemenkes RI. https://databoks.katadata.co.id/datapublish/2019/10/08/persebaranprevalensi-skizofreniapsikosis-di-indonesia\#

Makhruzah, S., Putri, V. S., \& Yanti, R. D. (2021). Pengaruh Penerapan Strategi Pelaksanaan Perilaku Kekerasan terhadap Tanda Gejala Klien Skizofrenia di Rumah Sakit Jiwa Daerah Provinsi Jambi. Jurnal Akademika Baiturrahim Jambi, 10(1), 39-46. http://dx.doi.org/10.36565/jab.v10i1.268

Manao, B. M., \& Pardede, J. A. (2019). Correlation of Family Burden of The Prevention of Recurrence of Schizophrenia Patients. Mental Health, 4(1), 31-42.

Pardede, J. A., \& Laia, B. (2020). Decreasing Symptoms of Risk of Violent Behavior in Schizophrenia Patients Through Group Activity Therapy. Jurnal Ilmu Keperawatan Jiwa,3(3), 291-300. http://journal.ppnijateng.org/index.php/jikj/article/view/621/338

Pardede, J. A. (2013). Pengaruh Acceptance And Commitment Therapy Dan Pendidikan Kesehatan Kepatuhan Minum Obat Terhadap Gejala, Kemampuan Berkomitmen Pada Pengobatan Dasar Kepatuhan Pasien Skizofrenia.

Pardede, J. A., Siregar, L. M., \& Halawa, M. (2020). Beban dengan Koping Keluarga Saat Merawat Pasien Skizofrenia yang Mengalami 
Perilaku Kekerasan. Jurnal Kesehatan, 11(2), 189-196. http://dx.doi.org/10.26630/jk.v11i2.1980

Pardede, J. A. (2020). Standar Asuhan Keperawatan Jiwa Dengan Masalah Risiko Perilaku. Kekerasan. https://doi.org/10.31219/osf.io/we7zm

Pardede, J. A., Simanjuntak, G. V., \& Laia, R. (2020). The Symptoms of Risk of Violence Behavior Decline after Given Prgressive Muscle Relaxation Therapy on Schizophrenia Patients. Jurnal Ilmu Keperawatan Jiwa, 3(2), 91-100. http://dx.doi.org/10.32584/jikj.v3i2.534

Pardede, J. A., Siregar, L. M., \& Hulu, E. P. (2020). Efektivitas Behaviour Therapy Terhadap Risiko Perilaku Kekerasan Pada Pasien Skizofrenia Di Rumah Sakit Jiwa Prof. Dr. Muhammad Ildrem Provsu Medan. Jurnal Mutiara Ners, 3(1), 8-14. http://114.7.97.221/index.php/NERS/article/view/1005

Pardede, J. A., Keliat, B.A., \& Yulia, I. (2015). Kebutuhan Dan Komitmen Klien Skizofrenia Meningkat Setelah Diberkan Acceptance And Commitment Therapy Dan Pendidikan Kesehatan Kepatuhan Minum Obat. Jurnal Keperawatan Indonesia, 3(18), 157-166. http://dx.doi.org/10.7454/jki.v18i3.419

Parwati, I. G., Dewi, P. D., \& Saputra, I. M. (2018). Asuhan Keperawatan PerilakuKesehatan. $\underline{h}$

Pitayanti, A., \& Hartono, A. (2020). Sosialisasi Penyakit Skizofrenia Dalam Rangka Mengurangi Stigma Negatif Warga di Desa Tambakmas Kebonsari-Madiun. Journal of Community Engagement in Health, 3(2), 300-303. https://jceh.org/index.php/JCEH/article/view/83/78

Putri, M., Arif, Y., \& Renidayati, R. (2020). Pengaruh Metode Student Team Achivement Division Terhadap Pencegahan Perilaku Kekerasan. Media Bina Ilmia,14(10), 3317-3326. http://ejurnal.binawakya.or.id/index.php/MBI/article/view/554/pdf

Suryenti, V. (2017). Dukungan Dan Beban Keluarga Dengan Kemampuan Keluarga Merawat Pasien Resiko Perilaku Kekerasan Di Klinik Jiwa Rumah Sakit Jiwa Provinsi Jambi Tahun 2017. Jurnal Psikologi Jambi, 2(2), 39-46. $\quad$ https://www.onlinejournal.unja.ac.id/jpj/article/view/4795 